\title{
冬小麦叶片暗呼吸对 $\mathrm{CO}_{2}$ 浓度和温度协同作用的响应
}

\author{
谭凯炎 $^{(1)}$, 周广胜 ${ }^{(12 *}$, 任三学 ${ }^{(1)}$ \\ (1) 中国气象科学研究院, 北京 100081 ; \\ (2) 中国科学院植物研究所, 植被与环境变化国家重点实验室, 北京 100093 \\ * 联系人, E-mail: gszhou@cams.cma.gov.cn \\ 2012-06-06 收稿, 2012-10-30 接受 \\ 国家自然科学基金(41075085)和国家重点基础研究发展计划(2010CB951303)资助
}

\begin{abstract}
摘要 植物暗呼吸的准确评估直接影响到植物碳收支估算. 为弄清气候变化对冬小麦叶片暗 呼吸的影响, 采用开顶式气室模拟研究了冬小麦叶片暗呼吸对不同 $\mathrm{CO}_{2}$ 浓度和温度的响应. 结 果表明, 冬小麦叶片暗呼吸速率随 $\mathrm{CO}_{2}$ 浓度升高呈线性下降趋势, $560 \mu \mathrm{mol} \mathrm{mol}{ }^{-1} \mathrm{CO}_{2}$ 浓度下 冬小麦叶片暗呼吸速率较 $390 \mu \mathrm{mol} \mathrm{mol}{ }^{-1} \mathrm{CO}_{2}$ 浓度下平均降低 $11 \%$. 冬小麦叶片暗呼吸速率与 温度呈指数关系, 暗呼吸温度系数 $Q_{10}$ 接近于 2 . 冬小麦叶片暗呼吸对温度和 $\mathrm{CO}_{2}$ 浓度的响应 是独立的, 据此建立了冬小麦叶片暗呼吸对 $\mathrm{CO}_{2}$ 浓度和温度协同作用的响应关系。研究成果可 为估算未来气候变化对冬小麦暗呼吸速率的影响, 采取科学的碳对策提供依据.
\end{abstract}

关键词

$\mathrm{CO}_{2}$ 浓度升高

温度

叶片暗呼吸

冬小麦
植物暗呼吸指植物在无光照条件下的有氧呼吸, 是植物体吸收氧气和放出二氧化碳的氧化还原过程, 它受外界环境包括温度、水分、 $\mathrm{O}_{2}$ 和 $\mathrm{CO}_{2}$ 等的影响. 因此, 植物暗呼吸是植物碳收支的重要组成部分 ${ }^{[1]}$. 准确评估植物固碳迫切需要弄清植物暗呼吸及其对 环境变化的响应. 作物和农田生态系统由于对气候 变化响应敏感而受到国内外研究者的高度关注, 但 现有研究主要集中于大气 $\mathrm{CO}_{2}$ 浓度(下文用 $\left[\mathrm{CO}_{2}\right]$ 表 示)、水分和温度变化对作物光合作用的影响 ${ }^{[26]}$ 以及 对农田生态系统土壤呼吸的影响 ${ }^{[7 \sim 10]}$, 关于作物呼吸 对 $\left[\mathrm{CO}_{2}\right]$ 、水分和温度变化及其协同作用响应的认识 严重不足 ${ }^{[11,12]}$, 制约着对作物呼吸作用的准确评估, 也影响着对作物产量的准确模拟. 当前, 尽管基于大 气 $\mathrm{CO}_{2}$ 富集(FACE) 试验和开顶式气室(OTC) 开展 了 $\left[\mathrm{CO}_{2}\right]$ 富集对大豆和水稻呼吸的影响研究, 但研究 结果分歧较大 ${ }^{[12 \sim 15]}$, 还没有建立其暗呼吸的定量评 价关系.

为增进作物呼吸对全球变化响应的理解并为准 确模拟作物固碳提供参数, 本研究试图以冬小麦为
研究对象, 基于开顶式气室对冬小麦进行 $\mathrm{CO}_{2}$ 熏气 处理, 结合夜间气温的大幅波动, 研究冬小麦叶片暗 呼吸对 $\left[\mathrm{CO}_{2}\right]$ 与温度变化协同作用的响应, 分析建立 冬小麦叶片暗呼吸对 $\left[\mathrm{CO}_{2}\right]$ 和温度变化协同作用响应 的关系.

\section{1 材料与方法}

(i ) 试验设计. 试验于 2011 2012 年在中国气 象科学研究院固城生态与农业气象试验站 (河北省定 兴县, $\left.39^{\circ} 08^{\prime} \mathrm{N}, 115^{\circ} 40^{\prime} \mathrm{E}\right)$ 进行. 该站位于华北山前平 原灌溉农业地区, 年均气温 $11.7^{\circ} \mathrm{C}$, 年均降水量 $551.5 \mathrm{~mm}$, 是中国冬小麦主要高产种植区之一. 土壤 为典型褐土, 有机质含量为 $12.1 \mathrm{~g} \mathrm{~kg}^{-1}$, 全氮为 0.56 $\mathrm{g} \mathrm{kg}^{-1}$. 试验在 3 个开顶式气室中进行, 气室为八边 形塑钢玻璃结构, 室内面积 $10 \mathrm{~m}^{2}$, 高 $2.5 \mathrm{~m}$, 由 2000 $\mathrm{m}^{3} \mathrm{~h}^{-1}$ 的离心风机通过 PVC 管道系统为气室均匀换 气. 试验设对照(大气浓度, $\mathrm{AC}$ ) 和两个 $\left[\mathrm{CO}_{2}\right]$ 升高处 理(EC), 其中一个 $\left[\mathrm{CO}_{2}\right]$ 升高处理气室从小麦返青至 成熟平稳进行 $\mathrm{CO}_{2}$ 熏气处理(设计浓度 $560 \mu \mathrm{mol} \mathrm{mol}^{-1}$, 2013, 58, doi: 10.1007/s11434-012-5605-1 
EC560), 另一个 $\left[\mathrm{CO}_{2}\right]$ 升高处理气室在进行呼吸观测 前 3 天将 $\left[\mathrm{CO}_{2}\right]$ 从 560 调高到 $700 \mu \mathrm{mol} \mathrm{mol}^{-1}(\mathrm{EC} 700)$, 持续到呼吸观测结束. 2011 年熏气处理自 2 月 26 日 持续到 6 月 9 日，熏气通常在日间进行，自呼吸观测 前 3 天开始, 熏气昼夜不停; 2012 年从 3 月 5 日至 6 月 10 日全期昼夜熏气. $\mathrm{CO}_{2}$ 气源为高纯度钢瓶气, 气 室 $\left[\mathrm{CO}_{2}\right]$ 用北分麦哈克公司生产的红外气体分析仪 (QGS-08C) 实时监测, 用转子流量计实时调节输气量. 2011 年试验期间, 对照(AC)和处理气室 I (EC560) 的 $\left[\mathrm{CO}_{2}\right]$ 分别为 $391 \pm 11$ 和 $567 \pm 28 \mu \mathrm{mol} \mathrm{mol}^{-1}$, 观测阶 段处理气室 II (EC700) $\left[\mathrm{CO}_{2}\right]$ 为 $694 \pm 34 \mu \mathrm{mol} \mathrm{mol}^{-1}$; 2012 年对照(AC) 和处理气室 I (EC560)的 $\left[\mathrm{CO}_{2}\right]$ 分别 为 $393 \pm 15$ 和 $564 \pm 32 \mu \mathrm{mol} \mathrm{mol}{ }^{-1}$, 观测阶段处理气室 $\mathrm{II}(\mathrm{EC} 700)$ 的 $\left[\mathrm{CO}_{2}\right]$ 为 $706 \pm 31 \mu \mathrm{mol} \mathrm{mol}{ }^{-1}$. 冬小麦采 用直播, 播种日期为 10 月 10 日, 品种为济麦-22, 属 半冬性品种, 各气室从播种开始采用统一的管理措 施，水分供应充足，播种时施底肥磷酸二铵 $60 \mathrm{~g} \mathrm{~m}^{-2}$, 返青后追施尿素和磷酸二铵各 $25 \mathrm{~g} \mathrm{~m}^{-2}$. 呼吸观测阶 段, 对照与处理气室的发育期基本一致, 夜间气温在 $10 \sim 24^{\circ} \mathrm{C}$.

(ii) 观测内容与方法. 冬小麦叶片暗呼吸观测 在小麦孕穗至乳熟期进行. 选择晴朗、静风的夜间, 采用美国产 $\mathrm{Li}-6400$ 光合作用仪原位测定小麦植株旗 叶的呼吸速率等参数, 利用 $\mathrm{CO}_{2}$ 小钢瓶控制叶室输 人浓度(观测浓度), 这样既可避免气室 $\left[\mathrm{CO}_{2}\right]$ 波动对 观测结果的影响, 也可以用来测定呼吸速率对短 时 $\left[\mathrm{CO}_{2}\right]$ 变化的响应. 观测在夜间 21:00 04:00 进行, 将观测浓度设定为各气室相应的处理浓度 $(390,560$, $700 \mu \mathrm{mol} \mathrm{mol}{ }^{-1}$ ) 以观测 $\left[\mathrm{CO}_{2}\right]$ 的长期影响, 每个处理 每时次观测 3 个叶片; 在 3 个气室选定叶片分别设 定 $\left[\mathrm{CO}_{2}\right]$ 递增 $\left(100 \sim 1000 \mu \mathrm{mol} \mathrm{mol}{ }^{-1}\right.$ ) 以观测 $\left[\mathrm{CO}_{2}\right]$ 短时 变化的直接影响, 每个浓度的响应时间为 $5 \sim 7 \mathrm{~min}$. 暗呼吸速率以 $\mu \mathrm{mol} \mathrm{CO} \mathrm{CO}_{2} \mathrm{~m}^{-2}$ 表示.

(iii) 数据处理. 采用 Excel 软件进行数据分析处 理和作图，用 SPSS 统计软件进行显著性分析.

\section{2 结果分析}

\section{1 冬小麦叶片暗呼吸对温度变化的响应}

植物呼吸速率随温度的变化遵从指数关系 ${ }^{[16]}$ :

$$
R_{\mathrm{d}}=K \cdot Q_{10}{ }^{\frac{T-25}{10}},
$$

式中, $R_{\mathrm{d}}$ 为暗呼吸速率 $\left(\mu \mathrm{mol} \mathrm{CO} \mathrm{CO}_{2} \mathrm{~m}^{-2} \mathrm{~s}^{-1}\right), Q_{10}$ 为暗呼 吸温度系数, 不同植物取值在 1.6 3.0 之间 ${ }^{[16]}$, 农作 物的 $Q_{10}$ 一般取 $2.0^{[16 \sim 18]} ; T$ 为温度 $\left({ }^{\circ} \mathrm{C}\right) ; K$ 为温度 $25^{\circ} \mathrm{C}$ 时的呼吸强度, 也称暗呼吸系数. 在 $\left[\mathrm{CO}_{2}\right]$ 和其他因 素不变时, 利用不同温度下呼吸速率观测数据可计 算出 $K$ 值和 $Q_{10}$ 值.

利用 2011 年冬小麦孕穗期 4 月 12 日夜间对照气 室(AC) 4 个时次的资料得到了 $R_{\mathrm{d}}$ 与 $T$ 的关系(图 1), 其中 $R_{\mathrm{d}}$ 取以 10 为底的对数, $T$ 为 Li-6400 观测的冠层 气温.

由拟合结果得出式(1)的 $K$ 和 $Q_{10}$ 分别为 1.577 和 1.977 , 进一步验证了农作物的温度系数 $Q_{10}$ 接近于 $2^{[16]}$. 因此, 孕穗期冬小麦叶片暗呼吸速率与冠层气 温关系可表示为

$$
R_{\mathrm{d}}=1.577 \times 2^{\frac{T-25}{10}} .
$$

式(2)表明, 冬小麦叶片暗呼吸随温度升高而增强, 温度每升高 $10^{\circ} \mathrm{C}$, 呼吸速率约增强 1 倍.

\section{2 冬小麦叶片暗呼吸对 $\left[\mathrm{CO}_{2}\right]$ 变化的响应}

(i ) 短期 $\left[\mathrm{CO}_{2}\right]$ 变化. 图 2 是 2011 年冬小麦开 花期和乳熟期在 3 种 $\left[\mathrm{CO}_{2}\right]$ 处理下观测到的叶片暗呼 吸速率对短时间 $\left[\mathrm{CO}_{2}\right]$ 变化的响应, 即叶片暗呼吸 对 $\left[\mathrm{CO}_{2}\right]$ 变化的直接反应. 不同处理中冬小麦叶片暗 呼吸速率随 $\left[\mathrm{CO}_{2}\right]$ 升高的变化趋势基本相同, 即叶片 暗呼吸速率随 $\left[\mathrm{CO}_{2}\right]$ 的短时增加而降低, 将小麦叶片 从较低 $\left[\mathrm{CO}_{2}\right]$ 环境移置于较高 $\left[\mathrm{CO}_{2}\right]$ 下, 叶片暗呼吸作 用受到抑制, 而将叶片从较高 $\left[\mathrm{CO}_{2}\right]$ 环境移置于较 低 $\left[\mathrm{CO}_{2}\right]$ 中, 叶片暗呼吸作用加强. 各处理之间没有 显示规律性的差异.

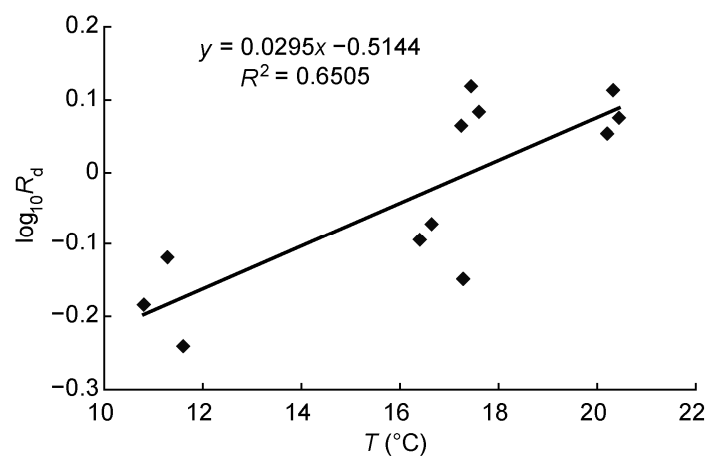

图 1 冬小麦叶片暗呼吸速率与温度的关系 

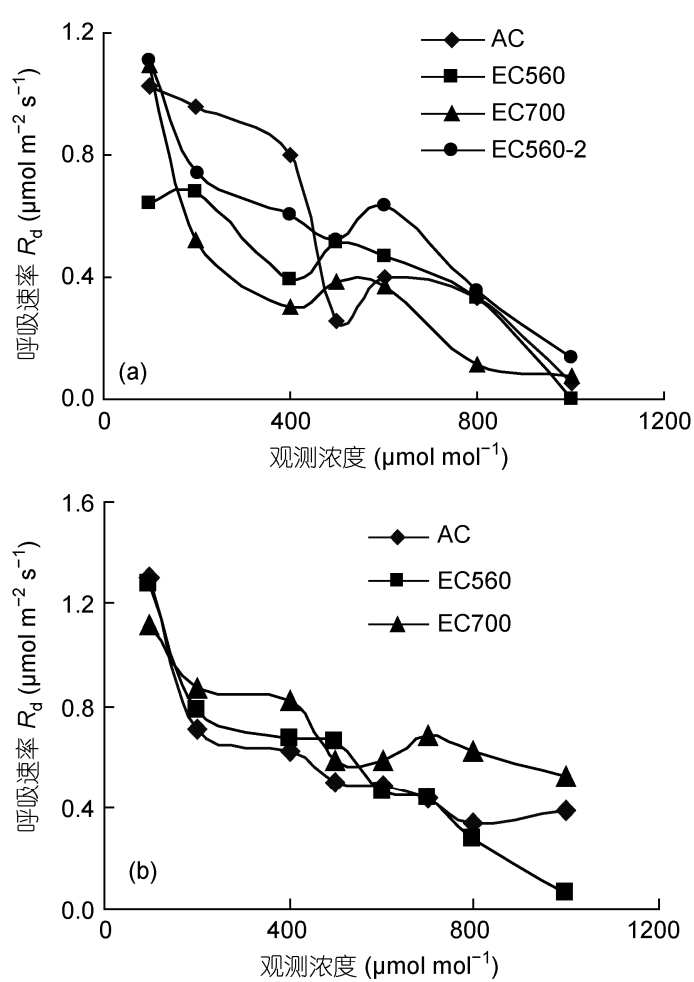

图 2 冬小麦叶片暗呼吸速率对短时间 $\left[\mathrm{CO}_{2}\right]$ 变化的响应 (a) 开花期; (b) 乳熟期. $\mathrm{AC}$, 对照 (大气 $\left[\mathrm{CO}_{2}\right]$ ); EC560, 处理 I $\left(560 \mu \mathrm{mol} \mathrm{mol}^{-1}\left[\mathrm{CO}_{2}\right]\right) ; \mathrm{EC} 560-2$, 处理 I 的重复观测; EC700, 处 理 II $\left(700 \mu \mathrm{mol} \mathrm{mol}^{-1}\left[\mathrm{CO}_{2}\right]\right)$

(ii) 长期 $\left[\mathrm{CO}_{2}\right]$ 升高. 2011 年在冬小麦孕穗期 和 2012 年在冬小麦灌浆始期观测了 3 个 $\left[\mathrm{CO}_{2}\right](390$, $560,700 \mu \mathrm{mol} \mathrm{mol}^{-1}$ ) 长期处理下的叶片暗呼吸速率. 在 $\mathrm{AC}$ 和 $\mathrm{EC} 560$ 气室中, 观测浓度与冬小麦生长环境 的 $\left[\mathrm{CO}_{2}\right]$ 相同, 在 EC700 气室中, 小麦已在观测浓度 中适应 3 天以上. 冬小麦生长环境的 $\left[\mathrm{CO}_{2}\right]$ 升高导致 冬小麦叶片暗呼吸速率减小(图 3), 其中冬小麦叶片 暗呼吸速率采用式(2)进行了温度订正. $560 \mu \mathrm{mol}$ $\mathrm{mol}^{-1}$ 浓度下冬小麦叶片暗呼吸速率较大气 $\left[\mathrm{CO}_{2}\right]$ 浓 度下平均降低 $11 \%$, 而 $700 \mu \mathrm{mol} \mathrm{mol}^{-1}$ 浓度下冬小麦 叶片暗呼吸速率较大气 $\left[\mathrm{CO}_{2}\right]$ 下平均下降 $25 \%$. 两年 的试验结果表明, 长期生长在高 $\left[\mathrm{CO}_{2}\right]$ 浓度下或在 高 $\left[\mathrm{CO}_{2}\right]$ 下经过较长时间适应后, 冬小麦叶片暗呼吸 速率都呈减小趋势, 即 $\left[\mathrm{CO}_{2}\right]$ 升高对冬小麦叶片暗呼 吸的长期影响效应表现为抑制作用.

(iii) 冬小麦叶片暗呼吸对 $\left[\mathrm{CO}_{2}\right]$ 变化的响应关系. 从图 2 和 3 可以看出, 冬小麦叶片暗呼吸对 $\left[\mathrm{CO}_{2}\right]$ 升 高的短期和长期响应均表现出相同的特征, 即在 100 1000 $\mu \mathrm{mol} \mathrm{mol}^{-1}\left[\mathrm{CO}_{2}\right]$ 内, 冬小麦叶片暗呼吸速

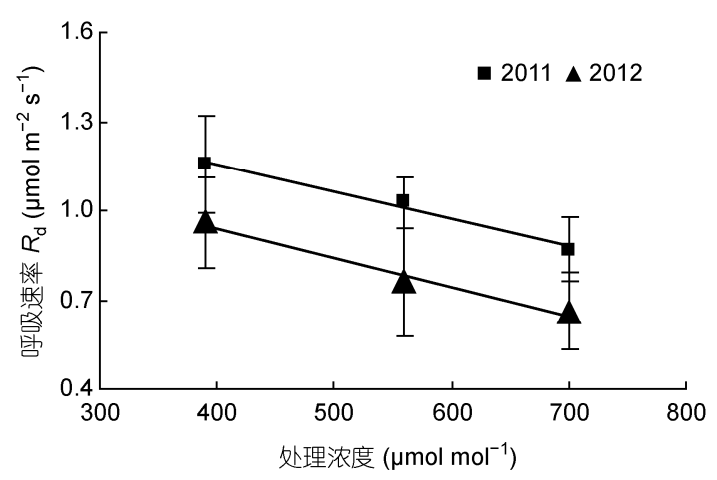

图 3 不同 $\left[\mathrm{CO}_{2}\right]$ 长期处理下的冬小麦叶片暗呼吸速率

率随 $\left[\mathrm{CO}_{2}\right]$ 升高呈下降趋势, $\left[\mathrm{CO}_{2}\right]$ 升高抑制了冬小麦 叶片暗呼吸. 图 3 中暗呼吸速率与 $\left[\mathrm{CO}_{2}\right]$ 呈很好的直 线相关关系，图 2 中两者关系用线性拟合效果好于其 他函数关系，但在更宽的 $\left[\mathrm{CO}_{2}\right]$ 区间，两者的相关关 系则可能符合幂函数关系. 为了简化计算, 在 100 $1000 \mu \mathrm{mol} \mathrm{mol}^{-1}\left[\mathrm{CO}_{2}\right]$ 内用线性关系来拟合叶片暗呼 吸速率与 $\left[\mathrm{CO}_{2}\right]$ 的相关关系. 由图 2 和 3 中资料得到 如下冬小麦叶片暗呼吸速率对 $\left[\mathrm{CO}_{2}\right]$ 变化的响应关 系:

$$
\begin{aligned}
& R_{\mathrm{d}}=1.520-0.00091 C_{\mathrm{CO}_{2}}\left(R^{2}=0.986, n=3, \text { 孕穗期 }\right), \\
& R_{\mathrm{d}}=0.917-0.00088 C_{\mathrm{CO}_{2}}\left(R^{2}=0.950, n=7, \text { 开花期 }\right), \\
& R_{\mathrm{d}}=1.330-0.00098 C_{\mathrm{CO}_{2}}\left(R^{2}=0.982, n=3, \text { 灌浆始期 }\right), \\
& R_{\mathrm{d}}=1.093-0.00086 C_{\mathrm{CO}_{2}}\left(R^{2}=0.837, n=8, \text { 釈熟期 }\right),
\end{aligned}
$$

式中, $R_{\mathrm{d}}$ 为叶片暗呼吸速率 $\left(\mu \mathrm{mol} \mathrm{CO} \mathrm{CO}_{2} \mathrm{~m}^{-2} \mathrm{~s}^{-1}\right), C_{\mathrm{CO}_{2}}$ 为 $\left[\mathrm{CO}_{2}\right]\left(\mu \mathrm{mol} \mathrm{mol}{ }^{-1}\right)$. 经 $t$ 检验, 4 个拟合关系均达到 极显著水平 $(P<0.01)$. 结果显示, 在冬小麦不同发育 期及不同温度条件下, 随 $\left[\mathrm{CO}_{2}\right]$ 增加, 叶片暗呼吸速 率下降速度基本一致, 即 $\left[\mathrm{CO}_{2}\right]$ 每增加 $100 \mu \mathrm{mol}$ $\mathrm{mol}^{-1}$, 叶片暗呼吸速率下降约 $0.09 \mu \mathrm{mol} \mathrm{CO}_{2} \mathrm{~m}^{-2} \mathrm{~s}^{-1}$. 这表明, $\left[\mathrm{CO}_{2}\right]$ 对冬小麦叶片暗呼吸速率的影响相对 独立, 不受发育期和温度的影响. 研究显示, $\left[\mathrm{CO}_{2}\right]$ 升 高对紫花苜宿植株叶片暗呼吸的影响与温度无关 ${ }^{[19]}$; 温度和 $\left[\mathrm{CO}_{2}\right]$ 对多种树叶暗呼吸作用的影响在很大程 度上是独立的 ${ }^{[20]}$. 本研究表明冬小麦叶片暗呼吸速 率对温度和 $\left[\mathrm{CO}_{2}\right]$ 的响应也是独立的.

归纳上述拟合关系，在 $100 \sim 1000 \mu \mathrm{mol} \mathrm{mol} \mathrm{m}^{-1}$ $\left[\mathrm{CO}_{2}\right]$ 内, 冬小麦叶片暗呼吸速率与 $\left[\mathrm{CO}_{2}\right]$ 关系可表示 如下:

$$
R_{\mathrm{d}}=R_{\mathrm{p}}-r \cdot C_{\mathrm{CO}_{2}},
$$

式中, $r$ 为 $\left[\mathrm{CO}_{2}\right]$ 影响系数, 可取 $0.0009 \mu \mathrm{mol} \mathrm{CO} \mathrm{m}^{-2} \mathrm{~s}^{-1}$; $R_{\mathrm{p}}$ 是不受 $\left[\mathrm{CO}_{2}\right]$ 影响的叶片暗呼吸强度, 受温度等环 
境因子的影响.

\section{3 冬小麦叶片暗呼吸对 $\left[\mathrm{CO}_{2}\right]$ 和温度协同作用 的响应关系}

依据上述分析, 将式(2)和(3)结合, 得出叶片暗 呼吸速率与 $\left[\mathrm{CO}_{2}\right]$ 和温度的综合关系式:

$$
R_{\mathrm{d}}=K_{\mathrm{p}} 2^{\frac{T-25}{10}}-r \cdot C_{\mathrm{CO}_{2}},
$$

式中, $K_{\mathrm{p}}$ 是温度 $25^{\circ} \mathrm{C}$ 时叶片暗呼吸强度, 将式中 $r$ 取 近似值 $0.0009 \mu \mathrm{mol} \mathrm{CO}_{2} \mathrm{~m}^{-2} \mathrm{~s}^{-1}$, 由观测资料回代式 (4)计算出 $K_{\mathrm{p}}$ 值, 结果表明 $K_{\mathrm{p}}$ 值在同一发育期比较稳 定, 标准差较小(表 1), 而在不同发育期则差异显著, 具有随发育期变化的明显特征, 在冬小麦孕穗至乳 熟期随生育进程呈减小趋势.

由各个时期的观测数据及同期的 $K_{\mathrm{p}}$ 值可得到冬 小麦叶片暗呼吸速率模拟值与实测值的关系(图 4). 独立资料检验结果表明, 式(4)可以较好地模拟温度 和 $\left[\mathrm{CO}_{2}\right]$ 对冬小麦叶片暗呼吸速率的协同影响.

\section{3 讨论}

目前, 关于冬小麦叶片暗呼吸速率对 $\left[\mathrm{CO}_{2}\right]$ 升高 的响应研究还很少. 对春小麦植株暗呼吸的试验显 示, 没有观测到短期 $\left[\mathrm{CO}_{2}\right]$ 变化的影响, 但长期生长

\section{表 $1 \quad K_{\mathrm{p}}$ 值随发育期的变化}

\begin{tabular}{lllll}
\hline & 孕穗期 & 开花期 & 灌浆始期 & 乳熟期 \\
\hline$K_{\mathrm{p}}$ 均值 ${ }^{\mathrm{a})}$ & $2.445 \mathrm{a}$ & $1.878 \mathrm{~b}$ & $1.578 \mathrm{c}$ & $1.354 \mathrm{c}$ \\
标准差 & 0.272 & 0.285 & 0.160 & 0.194 \\
\hline
\end{tabular}

a) 不同小写字母表示差异达显著水平 $(P<0.05)$

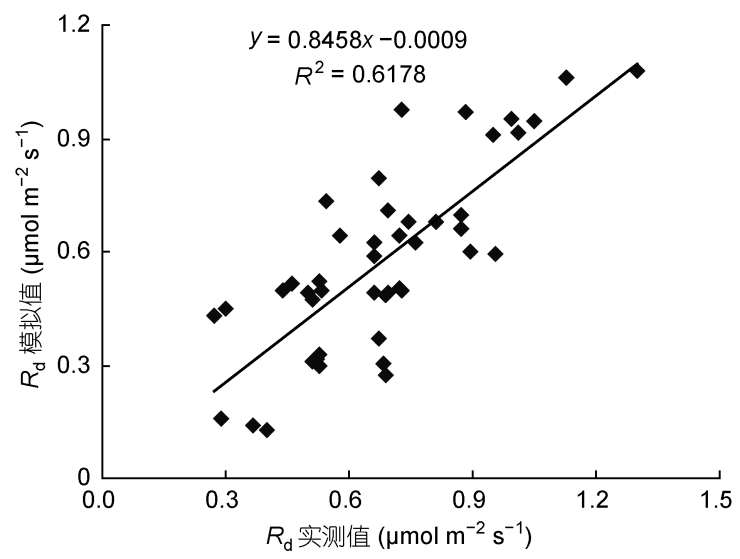

图 $4 R_{\mathrm{d}}$ 实测值与模拟值的关系
在 $\left[\mathrm{CO}_{2}\right]$ 加倍下春小麦植株的维持呼吸下降 $13 \%{ }^{[21]}$. 本研究显示, 生长在 $560 \mu \mathrm{mol} \mathrm{mol}{ }^{-1}\left[\mathrm{CO}_{2}\right]$ 下冬小麦 叶片暗呼吸速率较生长在 $390 \mu \mathrm{mol} \mathrm{mol}^{-1}\left[\mathrm{CO}_{2}\right]$ 下低 $11 \%$, 与春小麦观测结果相近 ${ }^{[21]}$, 但冬小麦叶片暗呼 吸速率对 $\left[\mathrm{CO}_{2}\right]$ 短期变化也非常敏感. 虽然一些试验 观测到作物叶片水平的呼吸速率不受 $\left[\mathrm{CO}_{2}\right]$ 升高影响 或随 $\left[\mathrm{CO}_{2}\right]$ 升高而加强, 但大量试验结果表明 ${ }^{[11]}$, 作 物冠层总呼吸在高 $\left[\mathrm{CO}_{2}\right]$ 下的增加比例要小于 $\left[\mathrm{CO}_{2}\right]$ 升高引起的生物量增长比例, 表明高 $\left[\mathrm{CO}_{2}\right]$ 下作物叶 片或植株的呼吸速率实际是减小的，而叶片水平的 观测结果可能受到其他因素的干扰.

大豆的 $\mathrm{CO}_{2}$ 富集试验表明 ${ }^{[13]}$, 采用不同单位表 示呼吸速率将影响叶片呼吸速率对 $\left[\mathrm{CO}_{2}\right]$ 升高的响应 特征, 如果采用单位叶面积的呼吸强度, $\left[\mathrm{CO}_{2}\right]$ 升高 对呼吸速率没有影响, 而用单位叶片干物重表示时, 呼吸速率则随 $\left[\mathrm{CO}_{2}\right]$ 升高显著减小, 因为高 $\left[\mathrm{CO}_{2}\right]$ 使单 位面积叶片干物重增加 $23 \%$. 本研究发现, 高 $\left[\mathrm{CO}_{2}\right]$ 也使小麦叶片比叶重略有增加(约 5\%, 图 5), 如果采 用干物重单位表示呼吸速率, 则 $\left[\mathrm{CO}_{2}\right]$ 升高对叶片呼 吸速率的抑制效果将更加显著.

本研究表明, 在 $\left[\mathrm{CO}_{2}\right]$ 和温度一定时, 冬小麦叶 片暗呼吸速率 $\left(K_{\mathrm{p}}\right)$ 在孕穗至乳熟期逐渐下降，与水稻 观测结果相似 ${ }^{[22,23]}$. 同时, 研究表明, 自然生长条件 下冬小麦体内氮素水平在拔节期后随生育进程下 降 ${ }^{[24]}$, 而多种作物的维持呼吸与氮含量呈显著正相 关 ${ }^{[25]}$. 孙文娟等人 ${ }^{[17]}$ 通过试验得出, 校正到 $25^{\circ} \mathrm{C}$ 的 小麦植株暗呼吸系数与氮含量 $(N)$ 呈正的直线相关关 系: $R_{\mathrm{d}}=4.74 N-1.45$. 据此推测, 本文的 $K_{\mathrm{p}}$ 值可能与叶 片 $N$ 呈正线性相关关系 (即 $K_{\mathrm{p}}=a+b N, a$ 和 $b$ 为常数). 但本研究中的 $K_{\mathrm{p}}$ 值是分离了 $\left[\mathrm{CO}_{2}\right]$ 影响后的呼吸特征 值, 而叶片氮含量是否受环境 $\left[\mathrm{CO}_{2}\right]$ 的影响还没有定 论. 研究显示, 在水分和氮供应适宜条件下, 高 $\left[\mathrm{CO}_{2}\right]$

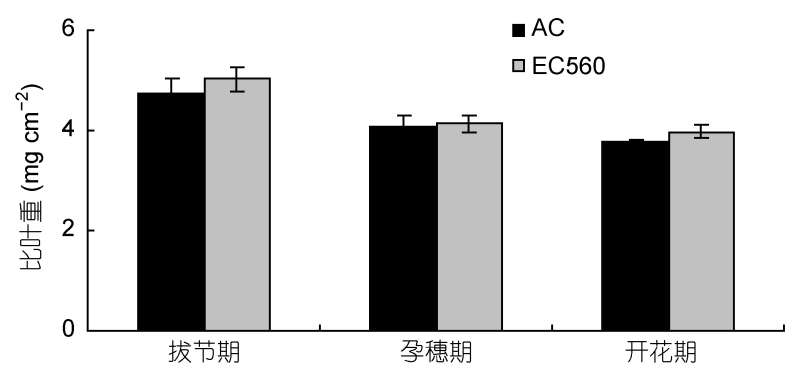

图 $5\left[\mathrm{CO}_{2}\right]$ 升高对小麦叶片比叶重的影响 $\mathrm{AC}$, 对照(大气 $\left.\left[\mathrm{CO}_{2}\right]\right) ; \mathrm{EC} 560$, 处理 I $\left(560 \mu \mathrm{mol} \mathrm{mol}{ }^{-1}\left[\mathrm{CO}_{2}\right]\right)$ 
处理对小麦叶片氮含量影响很小 ${ }^{[26]}$, 而 $\mathrm{CO}_{2}$ 富集处 理对大豆和水稻植株及叶片氮素含量的影响结果不 - ${ }^{[2,14,27,28]}$. 因此, $K_{\mathrm{p}}=a+b N$ 的推测是否成立还需要试 验验证.

作物暗呼吸测定难度较大, 暗呼吸速率本身较 小, 测值受到多种因素的影响, 数据离散度较大, 在 相差 $200 \mu \mathrm{mol} \mathrm{mol}^{-1}$ 的两个浓度水平上进行呼吸速率 对比观测，其测值一般难以表现出稳定的趋势. 本研 究(图 2)及相关研究 ${ }^{[18]}$ 的观测数据反映了这一现象. 通常, $\mathrm{CO}_{2}$ 富集试验多是在对照浓度水平上增加 200 $\mu \mathrm{mol} \mathrm{mol}{ }^{-1}$ 或对某个浓度加倍, 这可能是导致相关试 验结果不一致的原因之一. Tjoelker 等人 ${ }^{[29]}$ 对 12 种草 地植物的试验结果也证明了这一点. 在 360 和 700 $\mu \mathrm{mol} \mathrm{mol}{ }^{-1}$ 两个浓度上相比, 草地植物离体叶片的呼 吸速率变化在 $-6.4 \%$ 2. $4 \%$ 之间, 有增有减, 而在 $360 \sim 1300 \mu \mathrm{mol} \mathrm{mol}^{-1}$ 间的 5 个浓度上观测，则发现呼 吸速率随 $\left[\mathrm{CO}_{2}\right]$ 上升呈显著性的线性下降趋势。这说
明，在较大浓度区间进行多个浓度的观测有利于发 现呼吸速率随 $\left[\mathrm{CO}_{2}\right]$ 变化的规律性, 本研究结果再次 印证了这一点.

目前，关于作物暗呼吸速率与环境温度关系的

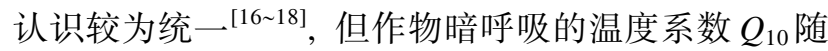
作物种类的不同是否存在差异及 $Q_{10}$ 值在不同温度区 间是否一致或如何变化还不统一. 本研究关于冬小 麦的 $Q_{10}$ 值来自于环境温度 $10 \sim 21^{\circ} \mathrm{C}$ 范围一夜中的 4 次观测结果, 其代表性需要进一步地验证.

\section{4 结论}

开顶式气室 $\mathrm{CO}_{2}$ 富集试验表明, $\left[\mathrm{CO}_{2}\right]$ 升高抑制 冬小麦叶片暗呼吸, 叶片暗呼吸速率随 $\left[\mathrm{CO}_{2}\right]$ 升高呈 线性下降, 叶片暗呼吸速率对 $\left[\mathrm{CO}_{2}\right]$ 升高的短期和长 期响应特征相同. 温度和 $\mathrm{CO}_{2}$ 浓度对冬小麦叶片暗 呼吸的影响相互独立，冬小麦叶片暗呼吸的温度系 数 $Q_{10}$ 接近于 2 .

1 Valentini R, Matteucci G, Dolman A J, et al. Respiration as the main determinant of carbon balance in European forests. Nature, 2000, 404: 861-865

2 林伟宏, 白克智, 匡廷云. 大气 $\mathrm{CO}_{2}$ 浓度和温度升高对水稻叶片及群体光合作用的影响. 植物学报, 1999, 41: 624-628

3 王修兰, 徐师华, 李枯祥, 等. 小麦对 $\mathrm{CO}_{2}$ 浓度倍增的生理反应. 作物学报, 1996, 22: 340-344

4 Kimball B A, 朱建国, 程否, 等. 开放系统中农作物对空气 $\mathrm{CO}_{2}$ 浓度增加的响应. 应用生态学报, 2002, 13: 1323-1338

5 Leakey A D B, Bernacchi C J, Dohleman F G, et al. Will photosynthesis of maize (Zea mays) in the US Corn Belt increase in future $\mathrm{CO}_{2}$ rich atmospheres? An analysis of diurnalcourses of $\mathrm{CO}_{2}$ uptake under free-air concentration enrichment (FACE). Glob Change Biol, 2004, 10: 951-962

6 Ainsworth E A, Rogers A. The response of photosynthesis and stomatal conductance to rising $\left[\mathrm{CO}_{2}\right]$ : Mechanisms and environmental interactions. Plant Cell Environ, 2007, 30: 258-270

7 李荣平, 周广胜, 王宇. 中国东北玉米农田生态系统非生长季土壤呼吸作用及其对环境因子的响应. 科学通报, 2010，55：12471254

8 Kou T J, Zhu J G, Xie Z B, et al. Effect of elevated atmospheric $\mathrm{CO}_{2}$ concentration on soil and root respiration in winter wheat by using a respiration partitioning chamber. Plant Soil, 2007, 299: 237-249

9 寇太记, 徐晓峰, 朱建国, 等. $\mathrm{CO}_{2}$ 浓度升高和施氮条件下小麦根际呼吸对土壤呼吸的贡献. 应用生态学报, 2011, 22: 2533-2538

10 任秀娥, 王勤学, 童成立, 等. 亚热带稻田生态系统土壤呼吸的估算. 科学通报, 2007, 52: 1548-1553

11 Gonzalez-Meler M A, Taneva L, Trueman R J. Plant respiration and elevated atmospheric $\mathrm{CO}_{2}$ concentration: Cellular responses and global significance. Ann Bot, 2004, 94: 647-656

12 Leakey A D B, Xu F, Gillespie K M, et al. The genomic basis for stimulated respiratory carbon loss to the atmosphere by plants growing under elevated $\left[\mathrm{CO}_{2}\right]$. Proc Natl Acad Sci USA, 2009, 106: 3597-3602

13 Bunce J A. Response of respiration of soybean leaves grown at ambient and elevated carbon dioxide concentrations to day-to-day variation in light and temperature under field conditions. Ann Bot, 2005, 95: 1059-1066 
14 Thomas R B, Criffin K L. Direct and indirect effects of atmospheric carbon dioxide enrichment on leaf respiration of Glycine max (L.) Merr. Plant Physiol, 1994, 104: 355-361

$15 \mathrm{Xu} \mathrm{Z} \mathrm{J,} \mathrm{Zheng} \mathrm{X} \mathrm{H,} \mathrm{Wang} \mathrm{Y} \mathrm{S,} \mathrm{et} \mathrm{al.} \mathrm{Effect} \mathrm{of} \mathrm{free-air} \mathrm{atmospheric} \mathrm{CO}_{2}$ enrichment on dark respiration of rice plants (Oryza sativa L.). Agric Ecosyst Environ, 2006, 115: 105-112

16 Amthor J S. The role of maintenance respiration in plant growth. Plant Cell Environ, 1984, 7: 561-569

17 孙文娟, 黄耀, 陈书涛, 等. 稻麦作物呼吸作用与植株氮含量、生物量和温度的定量关系. 生态学报, 2005, 25: 1152-1158

18 刘建栋, 王吉顺, 于强, 等. 作物夜间呼吸作用与温度、二氧化碳浓度的关系. 中国农业气象, 2002, 23: 1-3

19 Reuveni J, Gale J. The effect of high level of carbon-dioxide on dark respiration and growth of plants. Plant Cell Environ, 1985, 8: 623628

20 Tjoelker M G, Reich P B, Oleksyn J. Changes in leaf nitrogen and carbohydrates underlie temperature and $\mathrm{CO}_{2}$ acclimation of dark respiration in five boreal tree species. Plant Cell Environ, 1999, 22: 767-778

21 Gifford R M. Whole plant respiration and photosynthesis of wheat under increased $\mathrm{CO}_{2}$ concentration and temperature: Long-term vs. short-term distinctions for modeling. Glob Change Biol, 1995, 1: 385-396

22 Baker J T, Laugel F, Boote K J, et al. Effect of daytime carbon dioxide concentration on dark respiration in rice. Plant Cell Environ, 1992, 15: 231-239

23 邹建文, 黄耀, 郑循华, 等. 基于静态暗箱法的陆地生态系统一大气 $\mathrm{CO}_{2}$ 净交换估算. 科学通报, 2004, 49: 258-264

24 秦晓东, 戴廷波, 荆奇, 等. 冬小麦叶片氮含量时空分布及其与植株氮营养状况的关系. 作物学报, 2006, 1: 1717-1722

25 Michael G R. Effects of climate change on plant respiration. Ecol Appl, 1991, 1: 157-167

26 Sinclair T R, Pinte P J, Kimball B A, et al. Leaf nitrogen concentration of wheat subjected to elevated $\mathrm{CO}_{2}$ and either water or N deficits. Agric Ecosyst Environ, 2000, 79: 53-60

27 Leakey A D B, Ainsworth E A, Bernacchi C J, et al. Elevated $\mathrm{CO}_{2}$ effects on plant carbon, nitrogen, and water relations: Six important lessons from FACE. J Exp Bot, 2009, 60: 2859-2876

28 白克智, 钟泽璞, 丁莉, 等. 大豆对大气 $\mathrm{CO}_{2}$ 倍增的一些生理反应. 科学通报, 1996, 41: 164-166

29 Tjoelker M G, Oleksyn J, Lee T D, et al. Direct inhibition of leaf dark respiration by elevated $\mathrm{CO}_{2}$ is minor in 12 grassland species. New Phytol, 2001, 150: 419-424 